\title{
A tier-upon-tier march towards the impact factor
}

\author{
Paolo Martelletti
}

Published online: 26 June 2008

(c) Springer-Verlag 2008

Audentes fortuna juvat (Fortune favors the bold)

Virgil, Aeneid, X, 284

At the beginning of this year, as I wrote in my usual editorial addressed to the readers of The Journal of Headache and Pain (JHP) that "ISI inclusion represents our aim for the near future" [1], I certainly could not imagine that just at that time Thomson Reuters (formerly ISI) would include JHP in their indexing system, considered as the strictest and most selective organ among such control means of scientific quality. The reason why I could not know it was that I never submitted an evaluation request. Thomson Reuters/ISI independently co-opted JHP first in Derwent Drug File and then in Science Citation Index (SCI/SCI-E) with the first issue of 2008.

The news reached me during the 17 th IHRS Meeting in Chicago was taking place, and I felt very proud to announce this news to my colleagues. I also started making remarks, which I want to share with the readers of this journal.

The tier-upon-tier march that JHP had gone through during these years came back to my mind. I recalled its foundation in 1999, the first issue in 2000, the 4 years of positive internal opposition as Co-Editor, my first year as chair in 2004, the expansion from 4 to 6 issues per year and the almost immediate inclusion in PubMed/Medline, which had at the time an acceptance rate of $10 \%$, in June 2005. Today, 285 of the 585 published articles are indexed in PubMed/Medline.

P. Martelletti $(\square)$

Department of Medical Sciences, Second School of Medicine,

Sapienza University of Rome, Sant'Andrea Hospital,

Via di Grottarossa 1035, 189, Rome, Italy

e-mail:paolo.martelletti@uniroma1.it
A further crucial step was the partnership with the European Headache Federation (EHF), with which we shared strategic goals and a common support base [2]. The last stride to date is the inclusion in Derwent Drug File and then in the SCI/SCI-E database by Thomson Reuters/ISI (acceptance rate $15 \%$ ).

The accomplishment in such a short time of those significant targets implies that JHP fulfills the prerequisites of Thomson Reuters/ISI: quality of both content and layout, quality of publishing and cited authors, quality of editorial board, and timeliness.

The next stage will be, at last, automatic: after a 24-month evaluation period in Current Contents (2008-2009), JHP will have its impact factor (IF) in 2010. The IF will be published, as for other journals, in the Journal Citation Reports (JCR) in June 2011. In the meantime, calculation of citations and therefore virtual impact factor (VIF), which is an unofficial information, is possible through Web of Science (http://www. isiknowledge.com). At present, the VIF of JHP results interesting and competitive if compared with other area journals which already own IF.

An additional element which has helped to reach these achievements is a strong reduction in the rejection rate from $70 \%$ (2005) to $30 \%$ (2007), which reflects a leap in the quality of submitted manuscripts as well as the disappearance of low-profile manuscripts.

I wish to thank all the people who believed, and still believe, that headache medicine, too, needed competition. JHP can now take part in a sort of "Tri Nations". Not in rugby, of course, but in headache sciences. It is a honour for us to do so.

I also thank those who paid attention to the "moral suasion" which JHP has promoted since 2003 [3] towards a 
strong public health area devoted to headache medicine. Many individuals and initiatives such as the WHO Global Campaign Lifting the Burden have shared their resources with JHP in order to produce exciting means for the expansion of headache medicine into the medical as well as the social and political world.

This extraordinary intellectual ownership has to be shared with JHP's readership as a whole.

Conflict of interest None.

\section{References}

1. Martelletti P (2008) Thoughts on the past year of Journal of Headache and Pain. J Headache Pain 9:1-2

2. Martelletti P, Leonardi M (eds) (2003) International forum on global impact of migraine. J Headache Pain 4:S1-S90

3. Steiner TJ, Paemeleire K, Jensen R, Valade D, Savi L, Lainez MJ, Diener HC, Martelletti P, Couturier EG, European Headache Federation; Lifting The Burden: The Global Campaign to Reduce the Burden of Headache Worldwide; World Health Organization (2007) European principles of management of common headache disorders in primary care. J Headache Pain 8(suppl 1):S3-S47 